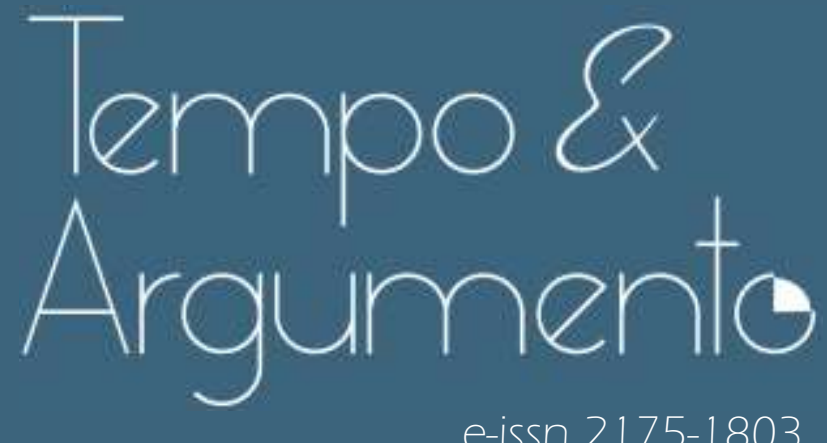

e-issn 2175-1803

\title{
Dimensões axiológicas fixadas em exercícios de livros didáticos de História
}

- Marcus Leonardo Bomfim Martins

Doutor em Educação pela Universidade Federal do Rio de Janeiro (UFRJ).

Professor da Faculdade de Eduação da Universidade Federal de Juiz de Fora (UFJF). Professor do Programa de Pós-Graduação em Educação da Universidade Federal de Juiz de Fora (PPGE/UFJF) e do Programa de Pós-Graduação em Ensino de História da Universidade Federal do Rio de Janeiro (ProfHistória/UFRJ).

Juiz de Fora, MG - BRASIL

lattes.cnpq.br/5012095935996528

marcus.bomfim@gmail.com

(D) orcid.org/0000-0003-3369-9260

Para citar este artigo:

MARTINS, Marcus Leonardo Bomfim. Dimensões axiológicas fixadas em exercícios de livros didáticos de História. Tempo e Argumento, Florianópolis, v. 13, n. 33, e0208, maio/ago. 2021.

dol http://dx.doi.org/10.5965/2175180313332021e0208

Recebido: $23 / 07 / 2020$

Aprovado: 18/03/2021 


\title{
Dimensões axiológicas fixadas em exercícios de livros didáticos de História
}

\begin{abstract}
Resumo
Assumindo como pressuposto que as dimensões axiológicas se articulam, inexoravelmente, a outros elementos no processo de configuração do conhecimento histórico escolar, e reconhecendo os exercícios e atividades do livro didático como um espaço de legitimação de saberes e de formas de com eles se relacionarem, a proposta deste artigo é explorar a empatia histórica como entre-lugar entre dimensão axiológica e recurso metodológico das relações de ensino-aprendizagem da História escolar. A partir de uma abordagem discursiva que reconhece o político como o lugar das disputas por hegemonização em qualquer ordem social, optou-se por, metodologicamente, analisar exercícios da coleção didática de História mais distribuída no Brasil. A proposta deste artigo se justifica pelos resultados obtidos de uma pesquisa de doutoramento concluída em 2019 na qual se constatou que, sem prejuízo de outros valores importantes, a empatia histórica relacionada a grupos historicamente subalternizados na estruturação das ordens sociais constitui-se como a principal questão axiológica fixada nesses exercícios/atividades.
\end{abstract}

Palavras-chave: Empatia histórica; conhecimento histórico escolar; exercícios de livro didático; livro didático de História; ensino de História.

\section{Axiological dimensions fixed in History textbooks exercises}

\begin{abstract}
Assuming that the axiological dimensions are inexorably linked to other elements in the school history knowledge setting, and recognizing the exercises and activities of the textbook as a gap between assessment and learning, the purpose of this article is to identify how the axiological dimension of historical empathy has been fixed in this space for the legitimation of knowledge and learning. From a discursive approach that recognizes the political as the place of disputes for hegemonization in any social order, it was decided, methodologically, to prioritize the reference texts to address issues, statements, templates, and the articulation with the curricular contents, in the analysis. The proposal of this article is justified by the results obtained in a doctoral research in which it was found that, without prejudice to other important values, empathy in relation to historically excluded and marginalized groups constitutes the main axiological issue fixed in these exercises/activities.
\end{abstract}

Keywords: Historical empathy; school history knowledge; textbook exercises; History textbook; history teaching. 


\title{
Introdução
}

\begin{abstract}
Houve um tempo em que o ensino da história nas escolas não era mais do que uma forma de educação cívica. Seu principal objetivo era confirmar a nação no estado em que se encontrava no momento, legitimar sua ordem social e política - e ao mesmo tempo seus dirigentes - e inculcar nos membros da nação - vistos, então, mais como súditos do que como cidadãos participantes - o orgulho de a ela pertencerem, respeito por ela e dedicação para servi-la. O aparelho didático desse ensino era simples: uma narração de fatos seletos, momentos fortes, etapas decisivas, grandes personagens, acontecimentos simbólicos e, de vez em quando, alguns mitos gratificantes. Cada peça dessa narrativa tinha sua importância e era cuidadosamente selecionada. (LAVILLE, 1999, p. 126)
\end{abstract}

A força explicativa dessa epígrafe encontra-se na identificação do vínculo entre o que se ensina em História nas escolas e os ideais de cidadania que se deseja formar. Se, como Laville (1999) destaca, durante algum tempo, certo tipo de civismo era considerado o único, ou talvez houvesse maior consenso de que era o melhor para formar os jovens que se tornariam futuros cidadãos, contemporaneamente o conceito de civismo tem sido objeto de disputas discursivas mais explícitas pela sua configuração.

Espera-se socialmente do ensino de História, e o é assim desde a sua institucionalização, que ele ajude a formar bons cidadãos por meio da vinculação de todos a um passado comum. Há, contudo, disputas sobre o que se considera ser 'bom cidadão' em cada tempo histórico. Os anos 80 e 90 do século XX no Brasil, no contexto de redemocratização após 21 anos de ditadura militar, se apresentam como momento mais explícito de mudança em relação ao tipo de cidadania a ser buscada por meio do ensino de História.

A mudança do foco do ensino, até então voltado para uma cidadania súdita (típica de regimes autoritários), em direção a uma cidadania participativa (típica de regimes democráticos), enseja movimentos que interferem diretamente nos valores a serem difundidos por meio do ensino dessa disciplina e, consequentemente, interpelam a configuração desse conhecimento que é objeto de ensino. Hoje, esse consenso encontra-se explicitamente ameaçado por projetos reacionários como o do Programa Escola Sem Partido, por exemplo, que tencionam hegemonizar uma perspectiva particular absolutamente conservadora do que seria cidadania democrática. 
Com efeito, o que se coloca em xeque é a significação de civismo na qual se deve apostar e investir, e não o ensino de História como espaço-tempo legítimo para uma formação dessa natureza, ainda que este mesmo autor advirta que "as pessoas se iludem sobre os efeitos reais da história ensinada" (LAVILLE, 1999, p. 125). De qualquer forma, essas disputas, bem como seus objetos, espaços, rastros e efeitos configuram o que o pesquisador espanhol Raimundo Cuesta Fernández nomeia como código disciplinar. Para ele, trata-se de um:

conjunto de ideias, valores, suposições, regulamentações e rotinas práticas (de caráter expresso e tácito) que se traduzem em discursos legitimadores e em linguagens públicas sobre o valor educativo da História, e que orientam a prática profissional dos docentes. Em suma, o elenco de ideias, discursos e práticas dominantes no ensino da História dentro do marco escolar. (CUESTA FERNÁNDEZ, 2009, p. 57, tradução nossa)

Assim como tudo o que se refere ao conhecimento histórico, que se singulariza pela relação que estabelece no e com o tempo, seu código disciplinar não é neutro, natural, com um fim previamente estipulado, controlado sempre de forma consciente pelos membros da comunidade disciplinar, imune a mudanças, mas algo que compreende uma infinidade de sujeitos, saberes e práticas que se articulam em uma complexa teia de significações que interpela a História e o seu ensino nas escolas da educação básica.

Nesse sentido, Cuesta Fernández (2009) entende a gênese do código disciplinar como processo de construção e não como ato de criação, destacando seu caráter histórico e contingente. O código disciplinar é, pois, visto como tradição social e, por isso, articula invenção, ao considerar as circunstâncias históricas, e reelaboração pelo não esquecimento dos fragmentos discursivos e práticas anteriores. Para ele:

O código disciplinar não é uma realidade estática, ainda que duradoura. Como toda tradição social que atua sobre os estratos conscientes e inconscientes da vida social, tende a conservação, mas ainda assim, como toda realidade social, é uma criação histórica e em si mesma contém também a possibilidade de mudança. (CUESTA FERNÁNDEZ, 2009, p. 57, tradução nossa)

O entendimento desse autor se coaduna com a perspectiva teórica escolhida para orientar as análises que serão feitas ao longo deste texto. Tal perspectiva 
teórica insere-se em uma postura epistêmica pós-fundacional, na qual o prefixo 'pós' não significa uma negação do fundamento, mas implica em "abrirmos mão de certezas e verdades apoiadas em fundamentos metafísicos que se situam fora do jogo da linguagem" (GABRIEL, 2013, p. 4). A dimensão política (ou o político) é o lugar da possibilidade da subversão, é a explicitação da precariedade dos fechamentos de sentidos, "é o que põe em xeque uma ordem constituída, demonstrando sua contingência" (MENDONÇA, 2012, p. 13).

Enfim, o político é o conflito que ao mesmo tempo constitui e coloca em risco o instituído, é a dimensão ontológica que constitui o social (LACLAU, 2005, p. 94), enquanto a política (e não a dimensão política) é a tentativa de controlar o político, de estabelecer uma ordem, é a hegemonização, a sedimentação, o fechamento de sentido, é a dimensão ôntica. Assim, embora se reconheça e valorize a empatia histórica como dimensão axiológica hegemonizada na configuração do conhecimento histórico escolar fixado em exercícios de livro didático, a perspectiva teórica assumida impede que tal hegemonização seja concebida como dada, reconhecendo, pois, seu caráter precário e contingente.

Tais esclarecimentos se fazem necessários à medida que contribuem para o entendimento de que o que se considera importante aprender em História está permanentemente sendo disputado no jogo político que configura a ordem social, não havendo, portanto, uma essência metafísica capaz de fechar para todo o sempre o sentido das dimensões axiológicas que animam o conhecimento histórico escolar. Assim, é possível afirmar que o código disciplinar da História está em processo contínuo de tensionamento em relação ao 'para que' e ao 'que' ensinar no âmbito dessa disciplina escolar, o que termina por influenciar o 'como ensinar', como a epígrafe trazida na abertura desse texto explicita.

A partir dos resultados obtidos de uma pesquisa de doutorado no campo do Ensino de História - finalizada em 2019, e que tinha como foco investigar as aprendizagens históricas validadas por meio de atividades propostas por exercícios de livros didáticos -, a proposta deste artigo é explorar a noção de empatia histórica situando-a num entre-lugar entre dimensão axiológica e recurso metodológico para as relações de ensino-aprendizagem dessa disciplina escolar. 
A opção por trabalhar com exercícios de livros didáticos se justifica pela importância desse texto curricular nas aulas da educação básica, sugerindo que os exercícios que ali contém sejam representativos do que a comunidade disciplinar (COSTA; LOPES, 2016), não sem disputas, considera importante ser aprendido, e que servem de base para a construção dos instrumentos avaliativos elaborados pelos docentes. Essa perspectiva se sustenta pelo fato de os livros passarem por um processo de avaliação por meio do Programa Nacional do Livro e do Material Didático1 (PNLD), indicando a validação daquele texto curricular, tornando-o legítimo para fazer parte das relações educacionais escolarizadas.

Para dar conta da proposta do artigo, divido-o em três partes. Na primeira, procuro situar o PNLD na interseção entre o código e a comunidade disciplinares da História, de forma a sustentar os exercícios de livros didáticos como espaçotempo de definição do que se considera válido em termos de aprendizagens escolares da História. Na segunda parte, exploro as especificidades epistemológicas do conhecimento histórico escolar de forma a argumentar favoravelmente ao caráter incontornável dos valores em seu processo de configuração e, por último, exploro alguns exercícios presentes na coleção didática selecionada de forma a identificar e problematizar as principais dimensões axiológicas ali fixadas com foco na questão da empatia histórica, ressignificada, simultaneamente, como valor e como recurso metodológico.

\section{Do código disciplinar à comunidade disciplinar da História: o que o PNLD tem a ver com isso?}

A escolha de exercícios de livros didáticos como campo empírico implica conhecer os limites que se impõem ao processo de validação das obras didáticas que poderão ser disponibilizadas para escolha por parte das diferentes escolas. Esses limites compreendem e sintetizam as disputas e as sedimentações

\footnotetext{
O Decreto no 9.099, de 18 de julho de 2017, unificou as ações de aquisição e distribuição de livros didáticos e literários, anteriormente contempladas pelo Programa Nacional do Livro Didático (PNLD) e pelo Programa Nacional Biblioteca da Escola (PNBE). Com nova nomenclatura, o Programa Nacional do Livro e do Material Didático - PNLD também teve seu escopo ampliado com a possibilidade de inclusão de outros materiais de apoio à prática educativa para além das obras didáticas e literárias: obras pedagógicas, softwares e jogos educacionais, materiais de reforço e correção de fluxo, materiais de formação e materiais destinados à gestão escolar, entre outros. Disponível em: http://portal.mec.gov.br/component/content/article?id=12391:pnld . Acesso em: 14 mar. 2021.
} 
provisórias que ocorrem em diversos espaços de produção de significados para a educação, de forma mais abrangente, e para o ensino da História, de forma mais específica.

Contudo, é indispensável sublinhar que tais limites não estancam a produção de sentidos sobre as atividades propostas nos livros e tudo o que elas legitimam, pois as apropriações que ocorrem no cotidiano da escola pelos sujeitos envolvidos na relação com o conhecimento e, atravessados pelos constrangimentos do contexto no qual estão inseridos, também produzem efeitos decisivos; em 'última' instância, no fechamento provisório de sentidos, mobilizando processos de identificação, subjetivação e objetivação. Reconhecer a sala de aula como instância 'última' da produção de sentidos não invalida a investigação sobre o que se chega até lá, nem tampouco confere a ela liberdade completa e absoluta em seu processo de significação, o que também não quer dizer que tudo possa ser previamente controlado.

Nesta seção, dedico-me a discutir sobre o código disciplinar da História no Brasil e como este se relaciona com sua comunidade disciplinar, sustentando que o PNLD se configura como efeito e expressão dessa relação, pois como informa o próprio Ministério da Educação (MEC):

As obras são inscritas pelos detentores de direitos autorais, conforme critérios estabelecidos em edital, e avaliadas por especialistas das diferentes áreas do conhecimento. Se aprovadas, compõem o Guia Digital do PNLD, que orienta o corpo discente e o corpo diretivo da escola na escolha das coleções para aquela etapa de ensino (Anos Iniciais do Ensino Fundamental, Anos Finais do Ensino Fundamental e Ensino Médio)². (BRASIL, c2018, grifo nosso)

Como as obras são compostas por livros destinados aos componentes curriculares das escolas da educação básica, há um corpo de especialistas de cada área do conhecimento responsável por avaliar as obras que são submetidas ao edital específico de convocação para as editoras que desejem vender sua(s) obra(s) ao governo federal. De forma simplificada, tal corpo de especialistas (mas não apenas eles) fazem parte da comunidade disciplinar, e os critérios e conhecimentos

\footnotetext{
${ }^{2}$ Disponível em: http://portal.mec.gov.br/component/content/article?id=12391:pnld. Data de acesso: 02 nov. 2018. No trecho citado, onde se lê "corpo discente", leia-se "corpo docente", pois são os professores e professoras que participam desse processo junto ao corpo diretivo das escolas. A informação está equivocada no site do MEC até a presente data (14, mar 2021).
} 
específicos por eles mobilizados no processo de avaliação configuram o código disciplinar, como desenvolverei mais adiante. Entretanto, a abordagem aqui levada a cabo não engessa tais espaços discursivos, de forma a supostamente definir qual deles ocupa a função de fundamento para o outro, mas opera com a ideia de que ambos estão em permanente construção e se influenciando mutuamente, acionando processos de identificação, subjetivação e objetivação em meio às relações de poder.

No campo do Currículo, o conceito de comunidade disciplinar ganhou notoriedade e consistência, nas últimas décadas do século XX, pelos estudos do pesquisador britânico Ivor Goodson - autor renomado em estudos curriculares em uma matriz crítica e sócio-histórica. De acordo com Costa e Lopes (2016), o autor entende que a comunidade disciplinar seria uma comunidade de profissionais docentes que se valem do nome da disciplina na luta por seus interesses, apoiando-se nos vínculos sociais dos processos de escolarização, de forma que é o vínculo profissional de indivíduos com determinada disciplina, aliado às tradições do campo disciplinar e da escolarização que configuram o pertencimento a uma comunidade.

Essa visão enfatiza a questão da profissionalidade e os interesses prévios dos sujeitos como condicionantes da possibilidade de fazer parte de uma determinada comunidade disciplinar. Mesmo conferindo importância ao campo disciplinar, entendo que Goodson (1997) termina por engessá-lo tal como o faz com os sujeitos potencialmente aptos a comporem a comunidade, ao definir previamente seus requisitos com base em uma relação específica com o objeto de ensino em questão.

Assumo, tal qual Costa e Lopes (2016), que a definição de comunidade disciplinar de Goodson (1997) não dá conta da compreensão do sujeito que se produz produzindo a política. Nesse sentido, entendo que "os campos disciplinares não são divisões epistemológicas, mas articulações políticas encadeadas por subjetivações contingentes envolvidas com as disciplinas." (COSTA; LOPES, 2016, p. 1012). Essa definição dos autores possui potencial heurístico para a compreensão de um caráter mais amplo tanto da comunidade, como do código disciplinar. Para esses autores: 
A comunidade disciplinar, por sua vez, não é o conjunto de profissionais que se organizam na defesa de seus interesses e carreira. A comunidade disciplinar, pela argumentação que construímos, é o conjunto de subjetividades constituídas em operações provisórias no campo discursivo da disciplina. A comunidade e as subjetividades/identificações não possuem uma origem, uma gênese. Seus saberes são construídos ao passo em que as subjetivações disciplinares também o são. É por meio de diferentes lutas políticas que campos disciplinares são organizados, organizando simultaneamente as identificações disciplinares. (COSTA; LOPES, 2016, p. 1028)

Essa definição de Costa e Lopes (2016) amplia significativamente o conceito de comunidade disciplinar se comparada à definição de Goodson (1997). Ela ajuda a romper, de alguma forma, com a ideia de um sujeito consciente, com subjetividade pré-existente, que age em função da satisfação de suas demandas. Ademais, essa definição não impede que se reconheça e identifique espaçotempos de tentativas de fechamento da inclusão de sujeitos (individuais ou coletivos) e subjetividades na cadeia discursiva que legitima determinadas configurações da comunidade disciplinar, como é o caso do PNLD.

Ao deslocarem o fundamento da comunidade disciplinar da profissionalidade e dos interesses prévios dos sujeitos para o político - o que torna esse fundamento contingente e precário, por ser disputado -, os autores permitem que todos aqueles que se relacionam de alguma forma com o objeto disciplinar, participando, pois, da produção de sentidos sobre ele, possam ser considerados membros daquela comunidade disciplinar. Não obstante, essa interpretação não considera que todos os sujeitos e subjetividades envolvidas se relacionem em posição de horizontalidade de poder, mas tampouco sugere que haja uma rigidez hierárquica que determine a 'vitória' dos interesses formulados no âmbito daqueles que socialmente desfrutam de maior legitimidade na relação com os saberes que compõem o objeto disciplinar.

Em outros termos, pode-se dizer que não apenas os historiadores, os pesquisadores vinculados às ciências da educação e os professores da educação básica compõem a comunidade disciplinar da História, mas também os estudantes, os dirigentes educacionais, setores da sociedade civil organizada, os movimentos sociais, o mercado de trabalho, as editoras de materiais didáticos, dentre outros, 
também dela fazem parte e animam as disputas por seu código disciplinar por meio da produção e articulação de demandas (RETAMOZO, 2009) que o interpelam.

Defender essa concepção de comunidade disciplinar não significa desconsiderar a importância do processo de institucionalização, cujo PNLD é sua maior expressão em termos de produção de livros didáticos, pois ele (ainda) representa - a despeito de movimentos de intervenção marcadamente conservadores, que colocam em risco algumas das conquistas desse programa em termos de ampliações democráticas - o compromisso público com uma educação socialmente referenciada na ciência, na cultura e na tecnologia. Trata-se, pois, de considerar esses elementos indispensáveis às cadeias discursivas definidoras de disciplina e conhecimento escolares no âmbito de cada área, isto é, do código disciplinar, enfim. Ademais, a institucionalização não impede as subjetivações/identificações disciplinares, ainda que se reconheça seu papel de legitimação de vozes e silêncios, o que tende a reafirmar as posições assimétricas das relações de poder, mas que, paradoxalmente, não determina as ações dos sujeitos no jogo político. Dessa forma, concordo com os autores que têm orientado a discussão sobre comunidade disciplinar, quando estes afirmam que:

os limites discursivos de uma comunidade disciplinar não podem ser definidos previamente às ações políticas. Tampouco podem ser enumerados os atores sociais que produzem sentidos parta as políticas de currículo, em nome de uma disciplina, como lideranças estáveis e estabilizadoras, como autoridades constituídas por um registro epistemológico, mesmo que socialmente construído, indiferente à própria política. Por intermédio do nome de uma disciplina escolar e da própria disciplinarização da escola, são sedimentadas interpretações curriculares, tenta-se estabilizar um currículo, ações pedagógicas são constituídas, para além e para aquém das ações dos profissionais docentes legitimados como porta-vozes desse nome. (COSTA; LOPES, 2016, p. 1027)

Importa sublinhar que, de acordo com a definição de comunidade disciplinar aqui assumida, para além da impossibilidade de controle completo de uma comunidade disciplinar, seu processo de institucionalização - aqui entendido como momento de sutura da expansão contínua de sujeitos individuais ou coletivos no interior dessa ordem social discursiva - tende a reafirmar a hierarquização social dos conhecimentos pela legitimação social das disciplinas escolares via campo universitário/científico. No entanto, como argumentado antes, é em cada sala de 
aula, em meio às relações de ensino-aprendizagem dos sujeitos que se produz um fechamento precário e contingente dessa comunidade:

uma dada comunidade contingente fala em nome da disciplina, decide em nome do que se supõe ser a verdade do conhecimento disciplinar. Por essa decisão a comunidade disciplinar é subjetivada, julga e se compromete, justifica ações e cria a história que sustenta a razoabilidade dessas mesmas ações e decisões. (COSTA; LOPES, 2016, p. 1028)

As objetivações produzidas por essa comunidade disciplinar configuram em cada espaço-tempo o código disciplinar. Assim, entendo que o PNLD se constitui como momento do corte antagônico responsável por definir contingencialmente o mínimo que se deve esperar do ensino de História em termos de objetivos, configuração do conhecimento escolar, aprendizagens, manutenção/subversão de tradições, o que interpela decisivamente no que aqui me serve de empiria, que são os exercícios. Assim, se o programa de avaliação dos materiais didáticos institucionaliza a comunidade disciplinar, também o faz em relação ao código disciplinar.

Como Cuesta Fernández (2009) salienta, o código disciplinar articula questões teóricas e práticas, não havendo, porém, nítida distinção entre elas. De todo modo, o conceito é suficientemente amplo para dar conta da epistemologia do conhecimento escolar e de questões metodológicas de seu ensino. Nesse sentido, tanto os editais como os guias do PNLD expressam fragmentos do que a comunidade disciplinar legitima, e é por ela (pelos fragmentos) constituída, revelando um processo dinâmico, complexo e não linear de relação entre a comunidade e o código disciplinares, rompendo assim com uma lógica tradicional segundo a qual primeiro se constitui uma comunidade para, a partir de então, torná-la responsável por elaborar um código. Como tem sido aqui defendido, nem mesmo a institucionalização encerra a produção de fluxos de sentidos que participam do processo de configuração de cada um desses elementos.

O processo avaliativo do PNLD é composto por critérios comuns e critérios específicos de cada área disciplinar que possuem caráter eliminatório. Os editais (BRASIL, 2016, 2017) que nortearam as avaliações da coleção que aqui será analisada especificam, no Anexo III de cada um deles, que a construção de 
conceitos e de posturas frente ao mundo é exigência para as propostas pedagógicas das obras didáticas, de forma a promover positivamente a imagem da mulher; abordar a temática de gênero em busca de uma sociedade não sexista; superar toda forma de violência; reafirmar os direitos humanos; valorizar a diversidade, a sustentabilidade e a cidadania; promover positivamente a imagem de afrodescendentes e dos povos do campo; abordar as relações étnico-raciais visando a construção de uma sociedade antirracista. ${ }^{3}$

Exigir a construção de conceitos, mais uma vez, evoca o código disciplinar. Quanto aos princípios, embora sejam atinentes a todas as disciplinas, a proximidade mais explícita da História com a formação cidadã, sugere que seja mais previsível que eles sejam mais trabalhados no âmbito dessa disciplina e, portanto, façam parte de seu código disciplinar, produzindo efeitos sobre as narrativas históricas escolares, as metodologias de ensino e as atividades que validam essas dimensões axiológicas. O disciplinar que adjetiva o substantivo código possui no tempo presente compromisso com valores, de forma que a referência a eles não se caracteriza como desvio dos objetivos de ensino, mas como condição para o seu desenvolvimento.

O vínculo inexorável entre questões axiológicas e educação escolar, e mais especificamente no ensino da História, não exime as relações de ensinoaprendizagem do compromisso com o valor de verdade (FORQUIN, 1993) dos conhecimentos que são objetos dessas relações. O PNLD reconhece isso ao determinar em ambos os editais que a utilização de modo equivocado ou desatualizado (considerando as conquistas científicas das áreas de conhecimento e os princípios de adequada mediação pedagógica) de conceitos e informações em exercícios ou atividades, bem como em outros espaços, leva à exclusão da obra.

Os editais (BRASIL 2016, 2017), tendo como norte a desconstrução das ideias de uma verdade absoluta, de memorização e de sequências lineares que dispensam a análise de processos, e a desestruturação de perspectivas históricas eurocêntricas, etnocêntricas e monocausais, destacam: o uso da interpretação histórica para compreensão do mundo; o desenvolvimento de conceitos

\footnotetext{
${ }^{3}$ Embora nos editais esses princípios estejam escritos de forma diferente entre eles, os sentidos são os mesmos.
} 
historicamente fundamentados; o pensar historicamente; a apresentação de argumentos historicamente fundamentados; a preocupação com anacronismo; a preocupação com voluntarismo; a superação da ideia de verdade absoluta e do extremo relativismo; a superação da memorização, do verbalismo e do acúmulo de conteúdos factuais; a compreensão dos processos de produção desse conhecimento; a aproximação dos conteúdos com o cotidiano dos estudantes.

É a configuração do código disciplinar que oferece, ao mesmo tempo, limites e possibilidades aos processos de subjetivação/identificação/objetivação no contexto da História ensinada. Em relação aos exercícios, para cumprir o papel de servir como corte antagônico do que vale ou não como aprendizagem histórica, eles precisam estar situados no que o código disciplinar oferece, mesmo reconhecendo que muitos desses elementos articulados tenham seu significado disputado. Tal reconhecimento deixa exposta a complexidade que caracteriza o momento do fechamento precário de seus sentidos, isto é, sua objetivação no âmbito do processo avaliativo por meio dos exercícios. No entanto, isso não impede que se busque identificar o que estes mesmos exercícios valorizam em termos axiológicos.

\section{Dimensões axiológicas e conhecimento histórico escolar: relações incontornáveis}

Proponho nesta seção argumentar teoricamente que as dimensões axiológicas são menos um objetivo a ser atingido por meio do ensino escolar da História, do que um elemento que configura esse saber. Não faz sentido, portanto, na perspectiva aqui assumida, dissociá-los.

O adjetivo escolar que acompanha o substantivo conhecimento histórico tem como função distingui-lo daqueles cujos focos não sejam especificamente o uso em situação de escolarização. Isso, no entanto, já pressupõe a existência de singularidades epistemológicas desse conhecimento. Assim, se há um escolar que qualifica certo conhecimento histórico, interessa aqui apresentar os elementos que o configuram, bem como o que serve como interrupção de seu processo de constituinte, servindo-lhe, pois, de exterior constitutivo. 
Defender a primazia ou exclusividade da ciência histórica como lugar de produção do objeto a ser ensinado nas escolas negligencia as singularidades da cultura escolar (e da cultura da escola) que interpelam as relações entre os sujeitos que circulam por esse espaço, e as relações desses sujeitos com os conhecimentos legitimados como objeto de ensino. A aposta que aqui faço é a da potência da incorporação das questões da cultura escolar no processo de produção do conhecimento escolar, sem que isso represente quebrar vínculos entre o conhecimento histórico acadêmico e o conhecimento histórico escolar e, ao mesmo tempo, não conceba este como um amálgama mal feito a partir daquele, pois "a incorporação de contribuições teóricas do campo da ciência de referência não produz uma réplica, mas sim um conhecimento com características originais, próprias da cultura escolar.” (GABRIEL; MONTEIRO, 2014, p. 34).

Na mesma linha de argumentação, Plá (2013) entende que o conhecimento histórico escolar não é apenas uma adaptação do conhecimento histórico acadêmico, tampouco um objeto desvirtuado política e ideologicamente. Trata-se de um conhecimento que constrói seus próprios regimes de historicidade e que possui suas próprias formas de verificabilidade. É uma forma particular, histórica e cultural de significar o passado. Para ele:

Ainda que vinculado de várias maneiras com o conhecimento científico, tem outra procedência que não é a fonte histórica ou o rigor acadêmico, e sim o uso público do passado dentro de uma sociedade. O resultado desse processo é o que denomino de conhecimento histórico escolar. (PLÁ, 2013, p. 475, tradução nossa)

Em outros termos, trata-se de incluir na cadeia equivalencial desse conhecimento escolar, elementos outros que não aqueles exclusivamente da ciência de referência, como destaca Gabriel (2017):

Trata-se assim de apostar na possibilidade de pensar a históriaensinada não mais como uma versão necessariamente simplificada e reduzida do conhecimento histórico produzido pelas pesquisas acadêmicas, mas sim como uma configuração de ordem epistemológica e axiológica (ética-político-cultural) com grau de especificidade e autonomia suficientes para que ela possa ser percebida e legitimada como um saber diferenciado e estratégico nas disputas pelas interpretações de sentidos do mundo. (GABRIEL, 2017, p. 25, grifo nosso) 
Os grifos assinalados no excerto apontam para a definição de limites no processo de configuração desse conhecimento, pois se esse saber não é o mesmo, tampouco uma versão reduzida do historiográfico, é preciso que haja mecanismos de preservação da sua condição de verdadeiro, para que ele seja legitimado para ser ensinado nas escolas. É, pois, no campo da Epistemologia que essas configurações são forjadas em meio às disputas que sinalizam a ausência de incompatibilidade entre questões de ordem política e epistemológica, principalmente quando o que está em jogo é um conhecimento que se diferencia dos demais pela centralidade de questões temporais para pensar a humanidade, o que implica, necessariamente, o apelo às questões axiológicas.

Reflexões no campo da Epistemologia reconhecem a diversidade de formas de conhecimento e seus processos de validação (MONTEIRO, 2007), pois a validade de apostar na epistemologia está na possibilidade de afirmar a existência de conhecimentos verdadeiros, válidos para serem ensinados em uma determinada área disciplinar (GABRIEL, 2017). Ou seja, defender a participação decisiva da cultura escolar no processo de produção dos saberes escolares não significa um 'tudo pode', pois o conhecimento escolar, nessa abordagem, é visto como "conhecimento com rigor teórico e metodológico, que representa uma perspectiva e que precisa ser validado pelos pares, sujeito necessariamente a críticas e superações." (MONTEIRO; PENNA, 2011, p. 192).

Assim, a epistemologia que confere o valor de verdade ao conhecimento histórico escolar não deve ser apenas aquela situada na ciência histórica, mas como defende Penna (2014), uma epistemologia que incorpore em suas reflexões questões relativas à função social dos saberes por meio do ensino. Incorporando questões de poder ao campo da epistemologia, Gabriel (2017) cunha o conceito de Epistemologia Social Escolar para dar conta das dimensões política e histórica como constituintes da noção de saber válido e legítimo para ser ensinado e aprendido nas escolas. Nesse caso, a articulação entre as culturas histórica e escolar seria o lugar no qual se estabelece o corte antagônico do que é e do que não é válido como conhecimento histórico escolar legítimo e verdadeiro. 
Considero fértil explorar a proposição de Plá (2013) sobre as ilusões que, em sua visão, ocultam as especificidades epistemológicas do conhecimento histórico escolar, para poder falar sobre a dimensão axiológica, concebida como incontornável, na estruturação desse saber. O autor aponta para a ilusão disciplinar como uma reafirmação do lugar da epistemologia da História científica como centro de legitimação da História escolar, o que contribui para um apagamento da especificidade desta ao colocar como polos binários e antagônicos a ciência e os valores, esvaziando a dimensão política que the é inerente pela função social que the é atribuída na formação cidadã específica do espaço escolar, e que contempla uma complexa teia de relações, pois ela se articula a:

tradições nacionalistas, intenções políticas, vínculos de derivação entre a historiografia profissional e a aula, definições psicológicas de aprendizagem, concepções pedagógicas que determinam as práticas docentes, prescrições curriculares que legitimam certas formas de pensar o passado, controles burocráticos, histórias de formação docente e história dos alunos que possuem suas próprias concepções de passado. (PLÁ, 2013, p. 475, tradução nossa)

Essa ilusão disciplinar pode ser entendida como efeito de outra ilusão, a científica. Nesta, há a crença de que o conhecimento ensinado é uma representação bastante fiel do conhecimento científico produzido pelos historiadores, fazendo com que quando a distância é percebida, seja vista como falsificação ou obstáculo à aprendizagem da 'verdadeira' história, reafirmando uma crença na equivalência epistemológica entre ambos os saberes (PLÁ, 2013). Dessa forma, a ilusão científica oculta uma condição irredutível do conhecimento histórico escolar: sua dimensão política.

Aliada a essas duas ilusões está a ilusão de neutralidade, que seria um efeito da ilusão científica na perspectiva de determinada racionalidade iluminista que concebe ciência como sinônimo de neutralidade e verdade. De acordo com o autor, "O conhecimento científico, entendido com o adjetivo de neutralidade e assepsia política e de classe social, ocultou e ainda oculta antagonismos políticos de grande envergadura" (PLÁ, 2013, p. 480, tradução minha). A relação entre as ilusões científica e de neutralidade pode ser explicada, segundo Plá (2013), pela necessidade de suavização do caráter político da História escolar, e a escrita de 
livros didáticos por historiadores contribui para a ilusão científica do que é político, pois como ele mesmo afirma:

O ensino de História se constitui por outro caminho, basicamente paralelo, a história como disciplina científica. Este feito é fundamental para compreender a ilusão de neutralidade dada pelo conhecimento científico ao ensino de História na atualidade, pois o que garante Cuesta Fernández é que o sentido do ensino de História encontra sua procedência na política, e não na ciência e que a posterior amalgamação entre historiografia e ensino de História tem a intenção de dotar de uma aparência científica o que é eminentemente político. (PLÁ, 2013, p. 479, tradução nossa)

É, pois, a dimensão axiológica do conhecimento histórico escolar que se pretende mitigar quando se promovem essas três ilusões, que são complementares, e cujo ponto nodal é o apagamento da especificidade epistemológica do saber histórico escolar. Apoiadas nos estudos de Michel Develay (1995), Monteiro (2007) e Gabriel (2017) entendem que o processo de didatização, isto é, de produção dos saberes escolares, é atravessado pela axiologização, correspondendo a uma "ética implícita”. Como afirma Monteiro (2007, p. 92), “a axiologização representa a opção feita no que tange à dimensão educativa, podendo expressar-se através da seleção cultural - ênfases - omissões negações”. Para Gabriel:

Confrontada com o ensino, a disciplina de História vê-se obrigada a lidar com a dimensão axiológica que lhe é inerente com muito mais acuidade. Tornam-se mais prementes e difíceis de serem negadas, escondidas ou adiadas as questões relativas aos sentimentos, vontades, virtudes, consciência de deveres, cuja explicitação em termos de finalidades de ensino e aprendizagem é, todavia, muito mais difícil de ser estabelecida. (GABRIEL, 2017, p. 27, grifo nosso)

A complexidade da articulação entre questões epistemológicas e axiológicas na configuração da história escolar criam o desafio de tornar a História ensinável ao mesmo tempo em que se garanta sua função formadora no plano cultural e político. Os instrumentos avaliativos - e os exercícios assim também podem ser pensados -, no âmbito dessa disciplina escolar, somam-se a esse desafio na medida em que são eles que, em última instância, vão definir as configurações legítimas desse conhecimento em termos de conteúdos, habilidades, competências e dimensões axiológicas. 


\section{Exercícios de História: que dimensões axiológicas fixadas?}

Argumentadas as defesas das dimensões axiológicas como elemento inexorável da configuração do saber histórico escolar e dos exercícios de livros didáticos como suporte material de legitimação desse saber e, consequentemente, de seus elementos constituintes, nesta seção, dedico-me a apresentar as principais dimensões axiológicas identificadas na coleção didática que serviu como empiria para a pesquisa da qual este artigo se origina, e a explorar a noção de empatia histórica, apostando em sua potência de entre-lugar entre valor e recurso metodológico a partir de dois exercícios retirados da coleção 'História, Sociedade e Cidadania' da Editora FTD e de autoria de Alfredo Boulos Junior. A escolha dessa coleção se deu pelo fato dela ter sido a mais distribuída no país a partir do PNLD 2017, para o ensino fundamental (9 ano), e PNLD 2018, para o ensino médio (3o ano), de acordo com dados do Fundo Nacional de Desenvolvimento da Educação $(\mathrm{FNDE})^{4}$.

As dimensões axiológicas fixadas nos exercícios, no entanto, não se restringem à empatia histórica. Os valores considerados válidos a trabalhar com os alunos que estão finalizando o ensino fundamental (9a ano), por meio do ensino de História, foram: combate ao etnocentrismo; uso responsável dos avanços tecnológicos; cultura da paz; liberdade; tolerância religiosa; e transparência na política. Com os estudantes que estão integralizando a educação básica (3o ano), os valores mobilizados foram: antirracismo; democracia; cidadania, indignação com a drogadição; cultura da paz; e combate ao antissemitismo. (MARTINS, 2019).

Esses valores aparecem vinculados a variados conteúdos distribuídos pela coleção. No entanto, foi possível perceber algumas sistematizações. É possível, pois, identificar que as questões axiológicas associadas a conteúdos que se referem à História do Brasil são democracia e empatia histórica. Quando o espaço privilegiado é o dos continentes africano e asiático, os valores destacados são o combate ao etnocentrismo, liberdade, empatia histórica, antirracismo e indignação com a drogadição. Já os valores de cultura da paz, cidadania e antissemitismo estão atrelados a conteúdos destinados a explicar as transformações ocorridas na

Disponível em: http://www.fnde.gov.br/programas/programas-do-livro/livro-didatico/dadosestatisticos Data de acesso: 27 jul. 2018. 
Europa, sobretudo no contexto entre guerras e no Leste Europeu após o fim da Guerra Fria e a desintegração do bloco soviético.

Analisando as dimensões axiológicas em relação aos conteúdos aos quais elas se vinculam, percebe-se que nas narrativas da história brasileira as mais mobilizadas parecem indicar esses elementos como desafios a serem enfrentados ou consolidados na contemporaneidade. Outros valores que fazem parte do mesmo campo semântico do significante paz estão articulados aos conteúdos de guerras, enquanto no estudo relativo à África predomina o antirracismo como postura a ser buscada.

As constatações apresentadas, no entanto, permitem que se levante uma questão que pode se tornar instigante para ser investigada no âmbito do Ensino de História, como forma de interpelar o processo de configuração do conhecimento histórico escolar em contexto de sala de aula: haveria algum conteúdo mais indicado para trabalhar determinado valor, ou os valores podem ser trabalhados como forma de abordagem, independentemente do conteúdo trabalhado?

Apresentado um breve panorama do coletivo das dimensões axiológicas identificadas na referida coleção, passo agora à análise de dois fragmentos de atividades/exercícios com vistas a mostrar como a questão da empatia histórica aparece nesses espaços privilegiados de legitimação de saberes, haja vista esta ter sido a dimensão axiológica mais presente nos exercícios da coleção escolhida. A análise considerou os textos de referência para as questões, seus enunciados, gabaritos, e a articulação com os conteúdos.

Imagem 1 - Enunciado e gabarito fomentando a empatia histórica

b) Dados do Incra mostram que entre 2010 e 2014 aumentou a concentração de terras no Brasil, com $47,23 \%$ das propriedades rurais em mãos de grandes fazendeiros. 0 que pode ser feito para acelerar a reforma agräria no Brasil?

A) Resposta pesscal.

b) Rasposta pestoal. Professor comentar quH a maiorla dos paices destemviviobs roatizou sua reforma agrária ha muito tempo, Os Estados Unidos Dor exernglo, reailzaram à sua ro século XiX: o Janis. na primeira matade do secilio $x x$

\section{Economia}

Quando Itamar Franco assumiu a presidência, a inflação de cerca de $30 \%$ ao mês continuava a corroer os salários, a inibir os investimentos e a empobrecer os trabalhadores. E, para agravar a situaçāo, a população já não acreditava mais em planos salvacionistas.

886 UNIDADE 12 | MEIO AMBIENTE E SAÚDE

Fonte: Boulos Junior (2017, p. 886). 
Na imagem 1 observa-se que o enunciado da questão apresenta dados que confirmam o aumento da concentração fundiária no Brasil e, em seguida, solicita que o aluno apresente possíveis soluções para que a reforma agrária possa se concretizar rapidamente no país. Tal como é formulado, tal enunciado mobiliza tacitamente o entendimento de que a reforma agrária é a melhor forma de enfrentamento do problema constatado pelos dados apresentados. Ao assumir essa premissa, o exercício proposto se aproxima de demandas históricas reparadoras, formuladas em meio à trajetória de exclusão que marca o acesso à terra no Brasil, e cujos movimentos sociais, liderados por trabalhadores sem-terra, constituem-se como expoentes dessa luta.

Na mesma linha, o gabarito apresentado para a questão destaca que "a maioria dos países desenvolvidos realizou sua reforma agrária há muito tempo". Por tratar-se de uma questão aberta, sem resposta 'certa', o gabarito procura validar a aposta na reforma agrária como principal forma de combate à concentração fundiária trazendo exemplos de nações reconhecidamente desenvolvidas, como é o caso dos Estados Unidos e do Japão. Fica evidenciada, portanto, uma perspectiva de empatia histórica com grupos excluídos pela concentração fundiária no Brasil.

A questão proposta está vinculada ao conteúdo 'O Brasil na nova Ordem Mundial', situado no livro destinado ao terceiro ano do ensino médio. A articulação entre os dados oficiais informados no enunciado e as considerações feitas no gabarito - aqui entendido como espaço do corte antagônico entre o que é e o que não é considerado legítimo e validado no âmbito de uma Epistemologia Social Escolar - aponta, simultaneamente, para a necessidade de reforma agrária como condição para que o Brasil galgue melhor situação no contexto da Ordem Mundial vigente, e para que se atente para as condições de vulnerabilidade econômica e social dos povos marginalizados quando a ordem social em questão é o acesso à terra no país, corroborando a perspectiva aqui assumida de pensar a dimensão axiológica como constitutiva do conhecimento histórico escolar sem abrir mão dos conteúdos produzidos na historiografia.

Sendo as questões relativas às temporalidades, o elemento que confere identidade ao conhecimento histórico, partilho do entendimento de Abud (2005) 
para quem a empatia, as analogias e as experiências vividas fazem parte de uma mesma cadeia de equivalências que participa do processo de significação de temporalidades que atravessam a produção de narrativas em cada aula de História na educação básica. Nesse sentido, na imagem 2 é possível observar como a empatia histórica se articula a esses outros elementos temporais.

Imagem 2 - Texto de referência e gabarito fomentando a empatia histórica

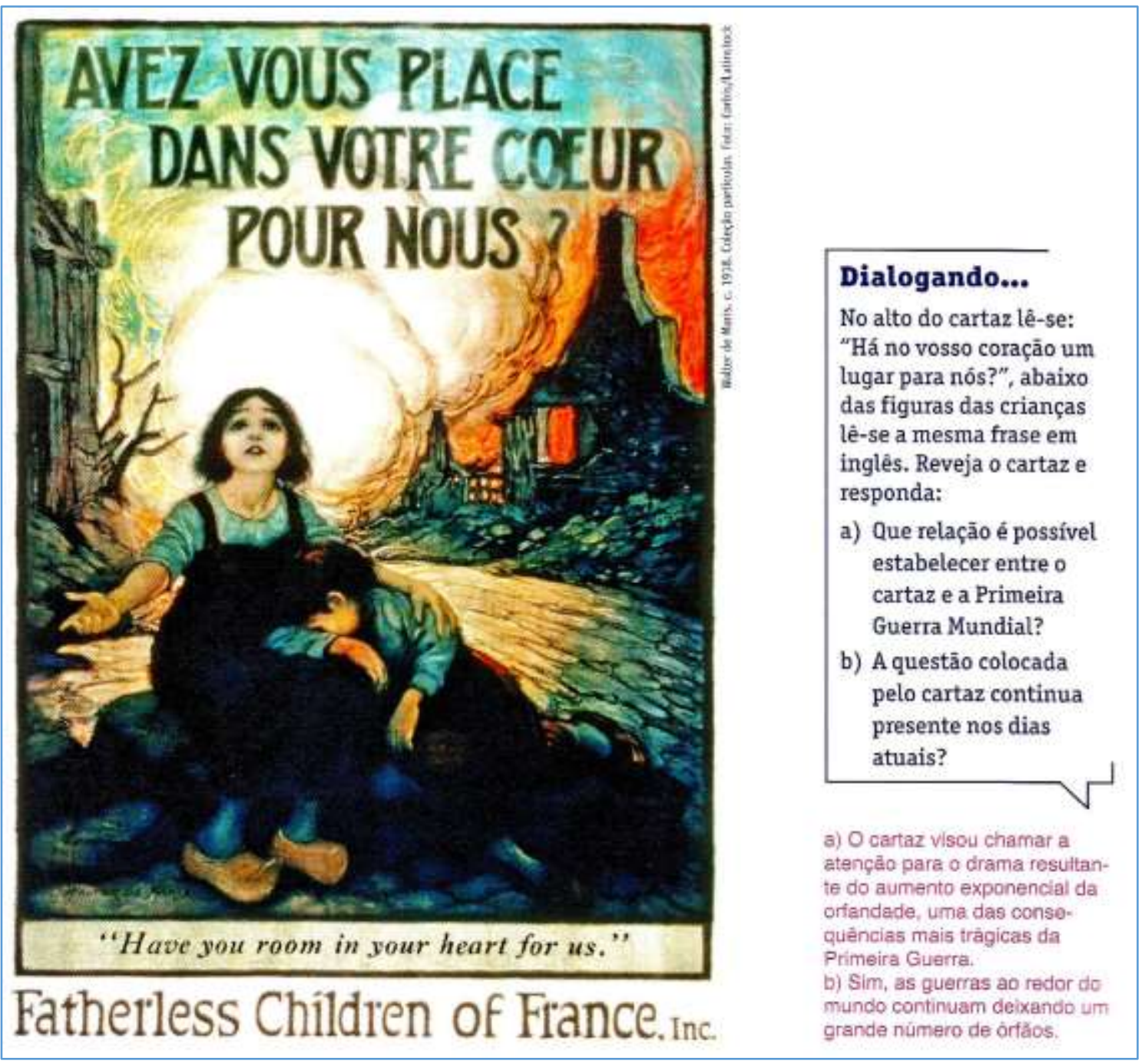

Fonte: Boulos Junior (2015, p. 39).

Identifica-se nos gabaritos apresentados a recorrência a um tema de preocupação contemporânea (a orfandade) aliado a um conteúdo específico (Primeira Guerra Mundial), mas que não se reduz a ele, como pode ser observado no item 'b’. A empatia histórica pode ser identificada também na articulação dos gabaritos com a fonte mobilizada para a formulação das questões da seção apresentada, pois se trata da imagem de um cartaz com crianças desamparadas 
em um cenário de destruição. A imagem assume a condição de fonte histórica, e não apenas de ilustração. A observação da dimensão temporal de permanência é ainda mais compreensível quando a resposta do item 'b' vincula o problema da orfandade aos efeitos de qualquer guerra, e elas continuam ocorrendo hoje. O exercício apresentado está presente em um capítulo cuja promoção da cultura da paz constitui-se como objetivo de promoção/consolidação axiológica.

Importa sublinhar que a noção de empatia histórica mobilizada nessa análise empírica não se reduz à forma como os estudos produzidos no âmbito da Educação Histórica no Brasil, na Inglaterra, no Canadá e na Espanha o entendem. Nesses estudos, a empatia histórica é mobilizada, geralmente, como recurso metodológico. Para Andrade et al. (2011, p. 261), inscritos nessa perspectiva teórica, trata-se da "capacidade de um sujeito se colocar no lugar de outro, de tentar pensar e ver o mundo com outros olhos, outras mentalidades, ainda que esses sujeitos sejam separados por longo período temporal.". Em outro exemplo, dessa vez de experiência internacional, essa mesma perspectiva permanece:

O tipo de exercícios planejados para fomentar compreensões históricas por empatia supõe projetar aos estudantes que adotem o ponto de vista de agentes ou personagens reais ou recriados em um cenário histórico (que poderiam criar ou saber, quais seriam seus interesses, etc.) com o objetivo de diferencia-lo claramente do próprio ponto de vista e do ponto de vista do historiador. Ao adotar esse ponto de vista é necessário que o estudante contemple e avalie as opções que estavam disponíveis ao personagem, tendo em conta os valores, crenças, ideologia dele e não as suas próprias. (DOMÍNGUEZ, 1993 apud SÁlZ SERRANO, 2013, p. 4, tradução nossa)

Na mesma perspectiva teórica, mas produzindo certo deslocamento, Pereira (2013, p. 8) entende que esse exercício "envolve entender o que pensou, sentiu o agente histórico e não ter o mesmo sentimento que ele”. Ao priorizar a perspectiva de metodologia, essa abordagem aposta no encontro com outros valores, situados em outros espaços-tempo, o que em si, não é necessariamente um problema. A maior ou menor validade dessa abordagem está diretamente relacionada aos objetivos docentes relacionados ao contexto concreto no qual a aula de História estiver se desenvolvendo. De forma a ampliar a potência da noção de empatia histórica, sublinhando seu caráter axiológico, recorro à Biesta (2017) para mobilizar a noção de "visita" com a qual opera esse autor, para ampliá-la em relação ao sentido de metodologia. Para este autor, 
- principal problema com a empatia é que ela pressupõe que podemos simplesmente (e confortavelmente) tomar a posição do outro, negando com isso tanto o caráter situacional de nosso próprio ver e pensar como o do outro. Visitar não é, portanto, ver pelos olhos de outra pessoa, mas ver com nossos próprios olhos a partir de uma posição que não é a nossa - ou, para ser mais preciso, numa história muito diferente da nossa. (BIESTA, 2017, p. 124, grifo do autor)

Esse é o deslocamento assumido para o termo empatia histórica neste texto: associá-lo à ideia de "visita" tal como formulada por Gert Biesta (2017). Sua potência está na possibilidade de tomar a pluralidade como ponto de partida, mas também como meta, o que viabiliza seu sentido de valor, isto é, de dimensão axiológica. Assim, os exercícios propostos, tanto na Imagem 1 como na Imagem 2, contribuem para o ato de visitar e, portanto, para fomentar a pluralidade. Afinal, como adverte Albuquerque Junior (2016, p. 26), “a finalidade precípua do ensino de História é a formação de valores, é a produção de subjetividades, é a construção de sujeitos capazes de conviver com a diversidade e a diferença, com o que não é familiar".

Se ficam evidentes formas distintas de operar com a noção de empatia histórica em diferentes estudos no campo do Ensino de História, há de se sublinhar que, em ambas as perspectivas, esse exercício de empatia histórica não corresponde apenas a uma capacidade emotiva/afetiva. Trata-se prioritariamente de uma dimensão cognitiva ou, em outros termos, de uma estrutura de inteligibilidade que interpela os processos de subjetivação, identificação e objetivação que se efetivam numa aula de História sem se opor à razão e ao conhecimento histórico produzido nos limites teórico-metodológicos da ciência de referência. Considerando o objeto de análise desse texto, percebe-se que as propostas fixadas nos exercícios dos livros didáticos articulam essa dimensão axiológica aos conteúdos didatizados no processo de configuração do conhecimento histórico escolar.

Além dos povos sem-terra na primeira questão (Imagem 1) e da orfandade retratada na outra questão (Imagem 2), as demais temáticas articuladas à empatia histórica na coleção analisada foram: povos colonizados; proteção dos animais; cidadãos sob regimes ditatoriais; habitantes do campo; populações pobres; povos perseguidos; discriminação racial; machismo; povos indígenas (MARTINS, 2019). Essas temáticas informam sobre o compromisso da disciplina História com grupos 
historicamente vulneráveis e posicionados nas mais diversas ordens sociais em posições de subalternidade. Assim, aprender História tem como um de seus sentidos hegemônicos a produção de subjetividades que expressem preocupação com os processos de produção de exclusões e desigualdades. Esse movimento consiste em uma forma particular de estabelecer relações entre passado e presente, e inclusive de futuro - pensado como "horizonte de expectativas" (KOSELLECK, 2006) -, uma vez que a utopia a ser perseguida é a de um mundo sem que diferenças sejam transformadas em desigualdades. Seja como metodologia, seja como valor, exercitar a empatia histórica exige deslocamento temporal, o que é indispensável para o processo de transformação de uma aula de História em um evento que deixe marcas nos sujeitos que nela se relacionam.

\section{Considerações finais}

A constatação de que a comunidade disciplinar da História legitima, por meio de exercícios de livros didáticos, determinados valores corrobora a dimensão política do ensino de História. Sendo a principal marca axiológica a empatia histórica na relação com grupos historicamente excluídos e marginalizados, percebe-se um sentido de ensinar e aprender História na educação básica voltado para a cidadania democrática, para utilizar o termo mobilizado por Laville (1999).

A análise empreendida constatou que, diferente das acusações que lhes são endereçadas, o ensino escolar da História escapa ao proselitismo ao articular valores aos conteúdos produzidos cientificamente no âmbito da ciência histórica, configurando assim o conhecimento histórico escolar. Como sustentado ao longo do texto, este, em sua especificidade, articula os fluxos de cientificidade (conteúdos) com as demandas de diferença (valores) em sua configuração que, embora não iniciada na sala de aula, tem nesse espaço o lócus definitivo de fechamento precário e contingencial de sentido. Nesse sentido, incluir valores nas aulas de História não significa desvirtuá-la de seu objetivo, mas cumprir a função política e intelectual de educar por meio de conhecimentos históricos escolares.

Se, tradicionalmente, a empatia histórica vem sendo pensada como recurso metodológico capaz de permitir aos estudantes da educação básica um deslocamento temporal para assumir a visão de outros sujeitos, neste texto foi 
proposto manter a perspectiva de deslocamento temporal, mas produzir um deslocamento de forma a concebê-la como dimensão axiológica capaz de permitir o ato de visitar, que significa pensar seus próprios pensamentos em uma história diferente da sua. O descentramento do sujeito torna-se condição sine qua non para esse ato que interpela os processos de subjetivação em meio à relação com conhecimentos históricos escolares. Tanto em uma perspectiva como na outra, o deslocamento temporal é inevitável.

Opto por finalizar este texto reafirmando que inquirir a relação entre o "para quê', o 'quê' e o 'como' ensinar nas aulas de História é que vai implicar o sentido de empatia histórica a ser mobilizada em cada contexto concreto. Ademais, vale sublinhar que reconhecer o caráter incontornável da dimensão axiológica na configuração epistemológica do conhecimento histórico escolar não significa admitir que qualquer valor pode fazer parte dele. O compromisso com a democracia e com os direitos humanos impele que se exclua tudo aquilo que os coloque em risco.

\section{Referências}

ABUD, Katia Maria. Processos de construção do saber histórico escolar. História \& Ensino, Londrina, v. 11, p. 25-34, jul. 2005. Disponível em:

http://www.uel.br/revistas/uel/index.php/histensino/article/view/11834. Acesso em: 05 set. 2018.

ALBUQUERQUE JUNIOR, Durval Muniz de. Regimes de historicidade: como se alimentar de narrativas temporais através do ensino de história. In: GABRIEL, Carmen Teresa; MONTEIRO, Ana Maria; MARTINS, Marcus Leonardo Bomfim (orgs.). Narrativas do Rio de Janeiro nas aulas de história. 1. ed. Rio de Janeiro: Mauad X, 2016. p. 21-42.

ANDRADE, Breno Gontijo et al. Empatia histórica em sala de aula: relato e análise de uma prática complementar de se ensinar/aprender a História. História \& Ensino, Londrina, v. 2, n. 17, p. 257-282, jul./dez. 2011. Disponível em: http://www.uel.br/revistas/uel/index.php/histensino/article/view/11239. Acesso em: 14 maio 2020.

BIESTA, Gert. Para além da aprendizagem: educação democrática para um futuro humano. 1. ed. Belo Horizonte: Autêntica Editora, 2017. 
BOULOS JUNIOR, Alfredo. 360 história, sociedade \& cidadania: volume único (Parte III). 3. ed. São Paulo: FTD, 2017.

BOULOS JUNIOR, Alfredo. História, sociedade \& cidadania, 9a ano. 3. ed. São Paulo: FTD, 2015.

BRASIL. Ministério da Educação. PNLD 2017: história - Ensino Fundamental anos finais. Secretária de Educação Básica - SEB - Fundo Nacional de Desenvolvimento da Educação. Brasília, DF: Ministério da Educação, Secretária de Educação Básica, 2016.

BRASIL. Ministério da Educação. PNLD 2018: história - guia de livros didáticos Ensino Médio. Secretária de Educação Básica - SEB - Fundo Nacional de Desenvolvimento da Educação. Brasília, DF: Ministério da Educação, Secretária de Educação Básica, 2017.

BRASIL. PNLD. Ministério da Educação, Brasília, c2018. Disponível em: http://portal.mec.gov.br/component/content/article?id=12391:pnld. Data de acesso: 02 nov. 2018.

COSTA, Hugo Heleno Camilo; LOPES, Alice Casimiro. A comunidade disciplinar em Goodson: impasses em um registro pós-estrutural. Revista Brasileira de Educação, [S.l], v. 21, n. 67, out./dez. 2016. Disponível em:

http://dx.doi.org/10.1590/S1413-24782016216751. Acesso em: 02 nov. 2018.

CUESTA FERNÁNDEZ, Raimundo. Sociogénesis de uma disciplina escolar: la historia. Barcelona: Pomares-Corredor, 2009.

DEVELAY, Michel. Savoirs scolaires et didactique des disciplines: Une encyclopédie pour aujourd'hui. Paris: ESF Editeur, 1995.

FORQUIN, Jean-Claude. Escola e cultura: as bases sociais e epistemológicas do conhecimento escolar. Porto Alegre: Artes Médicas, 1993.

GABRIEL, Carmen Teresa. Discurso, demandas e fronteira: articulações teóricometodológicas na análise de textos curriculares. Revista da FAEEBA - Educação e Contemporaneidade, Salvador, v. 22, n. 40, p. 55-67, jul./dez. 2013. Disponível em: http://www.revistas.uneb.br/index.php/faeeba/article/view/750. Acesso em: 26 jul. 2018.

GABRIEL, Carmen Teresa. O processo de produção dos saberes escolares no âmbito da disciplina de história: tensões e perspectivas. Educação Básica Revista, São Carlos, v. 3, n. 2, 2017. Disponível em: http://www.laplageemrevista.ufscar.br/index.php/REB/article/view/300. Acesso em: 23 nov. 2018. 
GABRIEL, Carmen Teresa; MONTEIRO, Ana Maria. Currículo de História e Narrativa: desafios epistemológicos e apostas políticas. In: MONTEIRO, Ana Maria et al. Pesquisa em ensino de história: entre desafios epistemológicos e apostas políticas. 1. ed. Rio de Janeiro: Mauad X: Faperj, 2014. p. 23-40.

GOODSON, Ivor. A construção social do currículo. Lisboa: Educa, 1997.

KOSELLECK, Reinhart. Futuro passado: contribuição à semântica dos tempos históricos. Rio de Janeiro: Contraponto: PUC-RJ, 2006.

LACLAU, Ernesto. La razón populista. Buenos Aires: Fondo de Cultura Econômica, 2005.

LAVILLE, Christian. Guerra de narrativas: debates e ilusões em torno do ensino de História. Revista Brasileira de História, São Paulo, v. 19, n. 38, p. 125-138. 1999. Disponível em: http://www.scielo.br/pdf/rbh/v19n38/0999.pdf. Acesso em: 09 nov. 2018.

MARTINS, Marcus Leonardo Bomfim. A (im)possibilidade da avaliação no ensino de História: uma análise a partir de exercícios de livros didáticos. 2019. Tese (Doutorado em Educação) - Universidade Federal do Rio de Janeiro, Rio de Janeiro, 2019.

MENDONÇA, Daniel de. O momento do político: indecidibilidade, decisão e ruptura. In: ENCONTRO DA ABCP, 8., 2012. Gramado. Anais [...]. [Porto Alegre: FURGS], 2012. Disponível em:

https://cienciapolitica.org.br/system/files/documentos/eventos/2017/02/momento -politico-indecidibilidade-decisao-e-ruptura-368.pdf. Acesso em: 09 jul. 2018.

MONTEIRO, Ana Maria. Professores de história: entre saberes e práticas. Rio de Janeiro: Mauad X, 2007.

MONTEIRO, Ana Maria; PENNA, Fernando de Araujo. Ensino de História: saberes em lugar de fronteira. Educ. Real., Porto Alegre, v. 36, n.1, p. 191-211, jan./abr., 2011. Disponível em: https://seer.ufrgs.br/educacaoerealidade/article/view/15080/11518. Acesso em: 23 nov. 2018.

PENNA, Fernando. A relevância da didática para uma epistemologia da História. In: MONTEIRO, Ana Maria et al. Pesquisa em ensino de história: entre desafios epistemológicos e apostas políticas. 1. ed. Rio de Janeiro: Mauad X: Faperj, 2014. p. 41-52.

PEREIRA, Juliano da Silva. Algumas reflexões sobre o conceito de empatia e o jogo de RPG no ensino de História. In: Simpósio Nacional de História, 27., 2013, Natal.

Anais [...]. Natal: anpuh, 2013. Disponivel em:

http://www.snh2013.anpuh.org/resources/anais/27/1364641045_ARQUIVO_ALGUMA 
SREFLEXOESSOBREOCONCEITODEEMPATIAEOJOGODERPGNOENSINODEHISTORIA .pdf. Acesso em: 07 mar. 2021.

PLÁ, Sebastián. La ilusión científica de la didáctica de la historia: provocaciones teóricas sobre el conocimiento histórico escolar. In: BLÁZQUEZ, Juan Carlos, LATAPÍ ESCALANTE, Paulina; TORRES SALAZAR, Hugo. Memoria del cuarto encuentro nacional de docencia, difusión y enseñanza de la historia; segundo encuentro internacional de enseñanza de la historia; tercer coloquio entre tradición y modernidade. Santiago de Querétaro: Reddieh, 2013. p. 474-483.

RETAMOZO, Martín. Las demandas sociales y el estudio de lós moviminetos sociales. Cinta Moebio, Santiago, v. 35, p. 110-127, 2009. Disponível em: http://www.facso.uchile.cl/publicaciones/moebio/35/retamozo.pdf. Acesso em: 21 jul. 2018.

SÁIZ SERRANO, Jorge. Empatía histórica, historia social e identidades: pensar históricamente la conquista cristiana de la Valencia musulmana con estudiantes de 2o ESO. Clío, [s.l.], n. 39, 2013. Disponível em: http://clio.rediris.es. Acesso em: 16 jul. 2020.

Universidade do Estado de Santa Catarina - UDESC

Programa de Pós-Graduação em História - PPGH

Revista Tempo e Argumento Volume 13 - Número 33 - Ano 2021 tempoeargumento@gmail.com 